\title{
Predição da Distribuição de Temperatura em Juntas da Liga de Alumínio 5052 H34 Soldadas pelo Processo Friction Stir Welding
}

\author{
João Paulo Pires ${ }^{1}$, Bruno Silva Cota ${ }^{1}$, Alexandre Queiroz Bracarense ${ }^{1}$, Bernardo Arbex Campolina ${ }^{1}$ \\ ${ }^{1}$ Universidade Federal de Minas Gerais - UFMG, Programa de Graduação em Engenharia Mecânica, Belo Horizonte, MG, Brasil.
}

Recebido: 07 Mar., 2018

Aceito: 09 Jul., 2018

E-mail: joaoppires@ufmg.br (JPP)
Este é um artigo publicado em acesso aberto (Open Access) sob a licença Creative Commons Attribution Non-Commercial, que permite uso, distribuição e reprodução em qualquer meio, sem restriçōes desde que sem fins comerciais e que trabalho original seja corretamente citado.
Resumo: O processo Friction Stir Welding (FSW) tem sido motivo de intensa pesquisa e tem ganhado relevância no setor produtivo devido às suas vantagens técnicas e econômicas. Inicialmente utilizado pela indústria automotiva e aeroespacial, o processo passou de uma simples técnica de soldagem de chapas finas de ligas de alumínio para um processo adaptável de grande utilização na união de ligas de metais leves, titânio, aço e outros metais duros de pequenas espessuras. Os modelos virtuais são os mais indicados na fase inicial de projetos industriais por minimizarem perdas, tais como: material, mão de obra e tempo. Sendo assim, tem-se como objetivo deste trabalho validar o modelo de soldagem pelo processo de FSW, disponível no software comercial Altair ${ }^{\circledR}$, definindo as condições iniciais e de contorno de modo a representar o cenário testado. As histórias térmicas derivadas da simulação foram comparadas com os resultados dos ciclos térmicos medidos durante a soldagem de chapas finas, por meio de uma análise estatística dos resultados e desvios relativos. Foram encontrados valores de 0,9311 e 0,9546 para o coeficiente $R^{2}$ para o lado de avanço e retrocesso respectivamente, o que evidenciou uma boa concordância entre resultados computados e suas contrapartes experimentais.

Palavras-chave: Friction stir welding; Soldagem; Temperatura; Simulação; Modelo.

\section{Temperature Distribution Prediction in 5052 H34 Aluminum Alloy Joints Welded by Friction Stir Welding Process}

\begin{abstract}
The Friction Stir Welding (FSW) process has been the subject of intense research and has gained relevance in the productive sector due to its technical and economic advantages. Initially used by automotive and aerospace industry, the process went from a simple welding technique for thin sheets of aluminum alloys to an adaptable process of extensive use for joining alloys of light metals, titanium, steel and other thin hard metals. The virtual models are the most indicated in the initial phase of industrial projects because it minimizes losses, such as: material, labor and time. Therefore, the objective of this work is to validate the virtual FSW process welding model, available in the commercial software Altair ${ }^{\circledR}$, defining the initial and boundary conditions in order to represent the tested scenario. The thermal histories derived from the simulation were compared with the results of the thermal cycles measured during the thin sheet welding, by means of statistical analysis of the results and relative deviations. We found values of 0.9311 and 0.9546 for the coefficient $R^{2}$ for the forward and backward side respectively, which showed a good correlation between the computed results and experimental counterparts.
\end{abstract}

Key-words: Friction stir welding; Welding; Temperature; Simulation; Model.

\section{Introdução}

O processo Friction Stir Welding (FSW) foi desenvolvido por Wayne Thomas e um grupo de pesquisadores no início da década de 1990 em Cambridge, no Reino Unido, e seu notável crescimento pode ser explicado pela possibilidade de união, com sucesso, de materiais até então considerados não soldáveis ou de difícil soldabilidade. E pela isenção de defeitos comuns aos processos de soldagem por fusão [1].

Desde a sua criação, houveram diversas tentativas para compreender os fenômenos físicos que ocorrem durante o processo FSW, que podem ser afetados pelas variáveis de soldagem e ainda determinar a qualidade da junta soldada [2]. Nos primeiros anos de pesquisa, após o descobrimento da técnica, os fenômenos foram estudados prioritariamente por ensaios experimentais que, por definição, tendem a ser demorados e dispendiosos. Nos últimos anos, a simulação computacional vem assumindo uma importância cada vez 
maior como ferramenta de aquisição de conhecimento e desenvolvimento da ciência, por possibilitar a redução do tempo de projeto e evitar gastos desnecessários com protótipos e ferramentas. Neste contexto, a modelagem numérica para o processo FSW pode ser representada por dois métodos principais: fluidodinâmico (simulação de fluxo de material e distribuição de temperatura) e mecânica dos sólidos (simulação de distribuição de temperatura, tensão e deformação).

He et al. [3] fez uma revisão bibliográfica abordando as principais técnicas de modelagem virtual para a caracterização do processo FSW, quanto à distribuição de temperatura e sobre as possíveis propriedades mecânicas da junta após a soldagem. Também em uma revisão bibliográfica, Hamza [2] evidenciou os atuais trabalhos envolvendo CFD (Computational Fluid Dynamics), assim como os fenômenos físicos que interferem nos resultados das análises. Além disso, o autor elenca as oportunidades de pesquisa futuras para as aplicações do processo FSW em simulações.

O processo de soldagem por FSW torna-se difícil de analisar quando desconsiderada a forma com que o calor é gerado durante o processo. De acordo com Mishra e Ma [4], o calor provém de duas fontes distintas: da deformação plástica e da fricção entre a ferramenta-chapa. A respeito da deformação plástica, ainda não se tem uma determinação experimental da parcela de energia que é transferida para a peça. Entretanto, simulações numéricas preveem que este valor está entre 6 e $20 \%$ para o processo FSW [5]. Schmidt et al. [6] afirmam que apesar dos esforços em se desenvolver modelos matemáticos que predizem a geração de calor e fluxo de material utilizando modelos com condições de contorno pré-definidas, ainda não existe um modelo satisfatório para descrever as condições de contato para o processo Friction Stir Welding.

A geração de calor durante o processo de soldagem por FSW ocorre devido ao atrito entre a ferramenta e a superfície do substrato. Armansyah et al. [7] aponta e equaciona as três fontes de calor do processo: o calor gerado pela superfície do ombro da ferramenta; o calor gerado pelo pino; o calor da superfície de contato com as chapas soldadas. O calor no ombro é atribuído à força axial provocada durante o deslocamento da ferramenta na chapa, no plano transversal. O calor gerado no pino, por sua vez, tem sua maior fonte advinda da rotação da ferramenta na parte interna da junta, no plano frontal. Já no caso da ponta do pino, o calor também se dá pela mesma fonte, porém nesse caso o plano é o transversal.

Schmidt et al. [6] ressaltam que a interpretação normal da Lei de Coulomb não é suficiente para representar um modelo para o processo FSW, pois é baseado apenas num par de contatos rígido. Para uma melhor representação devem-se considerar as três formas de contato possíveis, que são: o atrito de escorregamento, o atrito de aderência e a adesão/escorregamento parcial.

Frigaard [8] discorre a respeito dos resultados obtidos após a soldagem de ligas de alumínio Al 6082-T6 e Al 7108-T79 endurecidas por envelhecimento e os compara a um modelo térmico em elementos finitos. $O$ autor verificou uma diferença máxima de $10 \%$ entre os valores de pico, o que indicou uma boa correlação entre os resultados virtuais e experimentais.

Mimouni et al. [9] descreve o uso de um código fluido dinâmico utilizando o solver Ansys/Fluent ${ }^{\circledR}$ para a análise tridimensional utilizando método volumétrico por formulação Arbitrária Lagrangeana-Euleriana (ALE), uma vez que esta permite a solução de problemas que envolvem grandes movimentos relativos de superfícies móveis. O material utilizado para análise foi a liga Al 2017A e posteriormente foram realizados experimentos que além da correspondência entre os valores, medidos e previstos, mostraram a ocorrência da máxima temperatura na área de maior deformação. $\mathrm{O}$ pico de temperatura encontrado foi de $475{ }^{\circ} \mathrm{C}$ nas proximidades do ombro e pinos da ferramenta de solda, também foi verificado que este valor decresce conforme se afasta da zona de mistura, fato é característico dos processos de soldagem.

Rajesh [10] compara os valores de temperatura obtidos numérica e experimentalmente aos calculados via modelo em elementos finitos para soldagem por FSW numa liga de Al6061. As temperaturas máximas estimadas foram de $467{ }^{\circ} \mathrm{C}$ para a zona misturada (nugget) e $306^{\circ} \mathrm{C}$ para a Zona Termicamente Afetada (ZTA). Os valores de temperatura simulados para as regiões afastadas da zona de soldagem se distanciam dos resultados experimentais, o que foi justificado pelo autor, devido à desconsideração da difusividade térmica no modelo numérico. Neste contexto, esse projeto tem como objetivo realizar a análise numérica e experimental da distribuição de temperatura durante a soldagem da liga de alumínio $5052 \mathrm{H} 34$ pelo processo FSW, bem como realizar a verificação da correlação virtual físico. 
Predição da Distribuição de Temperatura em Juntas da Liga de Alumínio 5052 H34 Soldadas pelo Processo Friction Stir Welding

\section{Materiais e Métodos}

Serão descritos a seguir os procedimentos computacionais e experimentais empregados no desenvolvimento deste projeto, resumidos no fluxograma apresentado na Figura 1. Foi realizada a criação do modelo térmico via software, desenvolvimento do modelo numérico, determinação das repartições térmicas, realização do processo de soldagem experimental, aquisição do perfil térmico dos pontos pré-estabelecidos e o tratamento dos dados. Por último, foi realizada a correlação entre os resultados virtuais e físicos por meio da análise do coeficiente de determinação e do comportamento teórico previsto pela literatura.

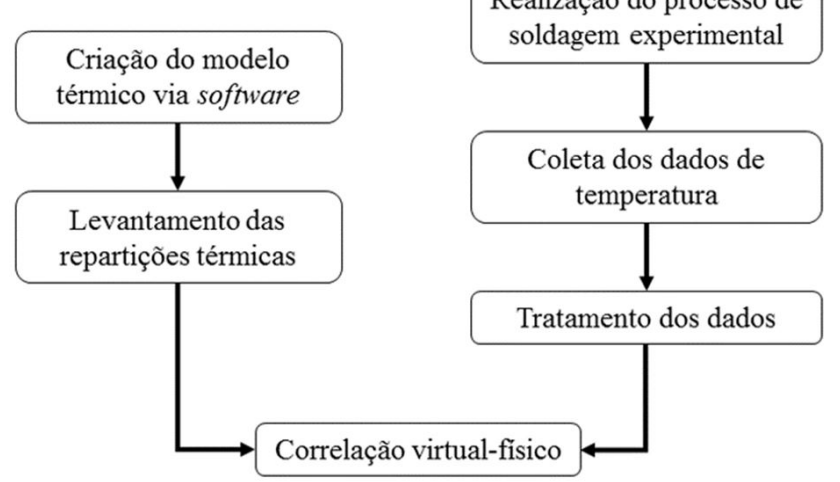

Figura 1. Fluxograma de identificação das fases do projeto.

\subsection{Desenvolvimento do modelo térmico}

Foi implementado um modelo virtual termomecânico não linear para determinar a distribuição da temperatura na junta soldada durante o processo Friction Stir Welding, em que foram empregados o software HyperWeld ${ }^{\circledR}$ e o solver HyperXtrude ${ }^{\circledR}$ que possuem uma extensão específica para o processo de soldagem por FSW. O modelo considerou a soldagem de topo, sendo a chapa presa nas extremidades e com a influência da convecção, condução e deformações plásticas da junta. A metodologia adotada para a criação do modelo térmico é apresentada na Figura 2.

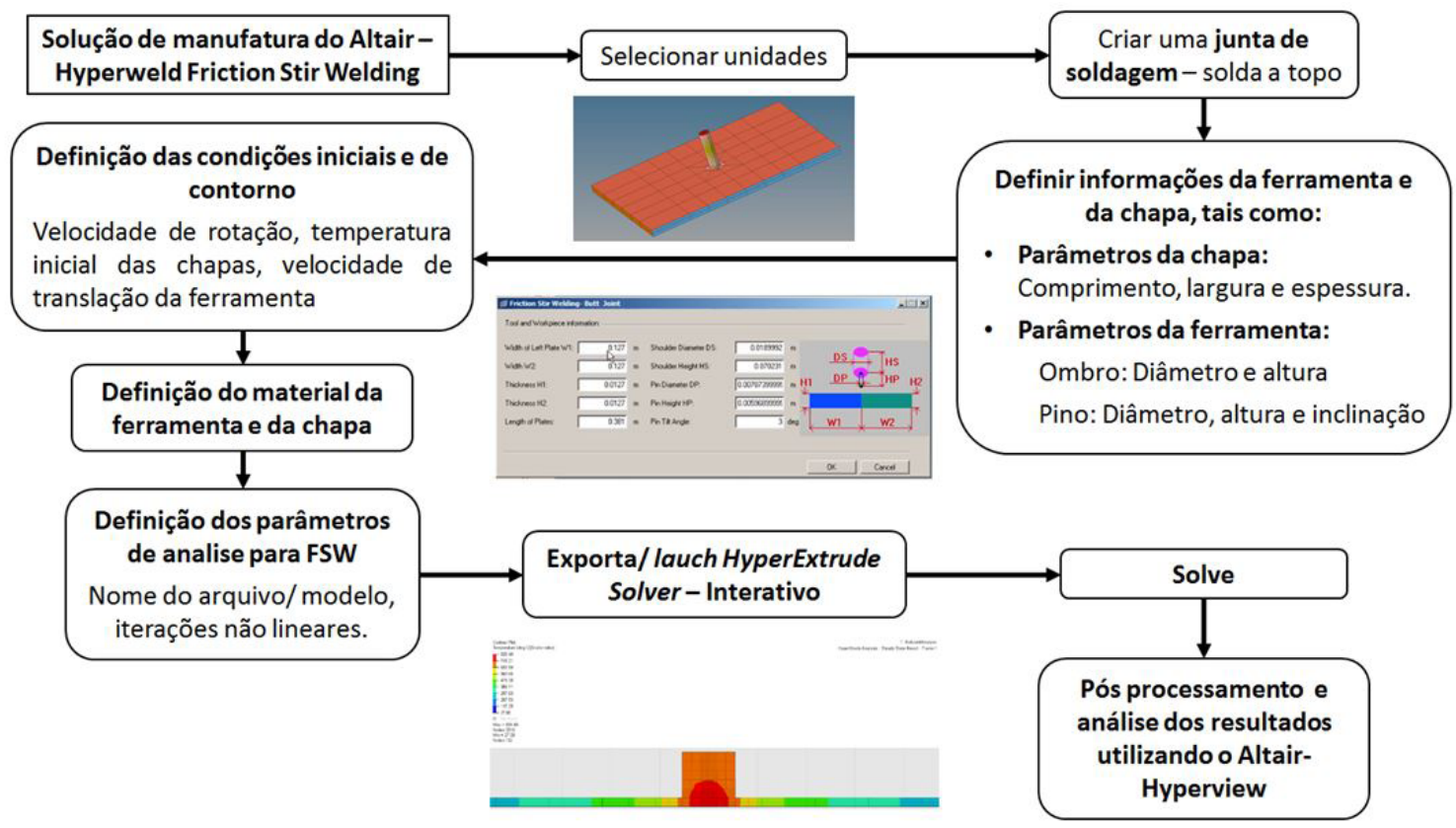

Figura 2. Metodologia para a realização da análise virtual utilizando o Altair HyperWeld-FSW ${ }^{\circledR}$ [11]. 
A modelagem do processo foi realizada no software HyperWeld ${ }^{\circledR}$, em que determinou-se os parâmetros geométricos do processo, que incluem as dimensões da chapa (comprimento, largura e espessura) e da ferramenta utilizada (diâmetro do ombro, diâmetro do pino e comprimento do pino). Os demais parâmetros do processo considerados no modelo são apresentados na Tabela 1 e as propriedades térmicas da liga de alumínio 5052 H34 (calor específico e a condutividade térmica) foram inseridas utilizando a biblioteca do software. Para este modelo, as chapas foram consideradas engastadas lateralmente e $\mathrm{o}$ ar $\mathrm{e}$ a base de soldagem como os elementos externos de troca de calor.

Tabela 1. Parâmetros do processo considerados no modelo virtual.

\begin{tabular}{lc}
\hline \multicolumn{1}{c}{ Propriedade } & Valor \\
Temperatura inicial - chapa & $27{ }^{\circ} \mathrm{C}$ \\
Velocidade de translação - ferramenta & $0,125 \mathrm{~mm} / \mathrm{s}$ \\
Velocidade de rotação - ferramenta & $378 \mathrm{rpm}$ \\
Coeficiente de atrito & 0,3 \\
Coeficiente convectivo superfície & $20 \mathrm{w} / \mathrm{m}^{\circ}{ }^{\circ} \mathrm{C}$ \\
Coeficiente convectivo ferramenta & $10 \mathrm{w} / \mathrm{m}^{2}{ }^{\circ} \mathrm{C}$ \\
\hline
\end{tabular}

Schmidt et al. [6] evidencia que, uma vez que o deslizamento é a condição predominante, o coeficiente de atrito deve atingir valores entre 0,27 e 0,35. Dessa forma foi adotado o valor médio de 0,3 , baseado nos estudos realizados pelo autor para o mesmo processo adotado neste trabalho. Os valores teóricos para os coeficientes convectivos utilizados foram de $20 \mathrm{w} / \mathrm{m}^{20} \mathrm{C}$ para a superfície e $10 \mathrm{w} / \mathrm{m}^{20} \mathrm{C}$ a ferramenta, conforme realizado por Yatapu et al. [12] em procedimento de soldagem a FSW em liga de alumínio via software Altair ${ }^{\circledR}$.

\subsection{Realização do processo de soldagem experimental}

\subsubsection{Equipamento de soldagem}

Para este projeto, foi usado o sistema robótico dimensionado por Cota et al. [13] para a soldagem de materiais com elevado ponto de fusão pelo processo Friction Stir Welding. A montagem experimental realizada é apresentada na Figura 3, em que é possível verificar o robô antropomórfico COMAU SMART NJ500 de 6 graus de liberdade (A) que foi usado para a adaptação do sistema de soldagem projetado (B). A base de soldagem é a mesa de uma furadeira de coluna adaptada como estrutura para a fixação das chapas a serem unidas pelo processo FSW (C). Para fazer o controle da rotação do sistema de soldagem foi utilizado um inversor de frequência com capacidade de acionamento de motores de até $50 \mathrm{cv}$.

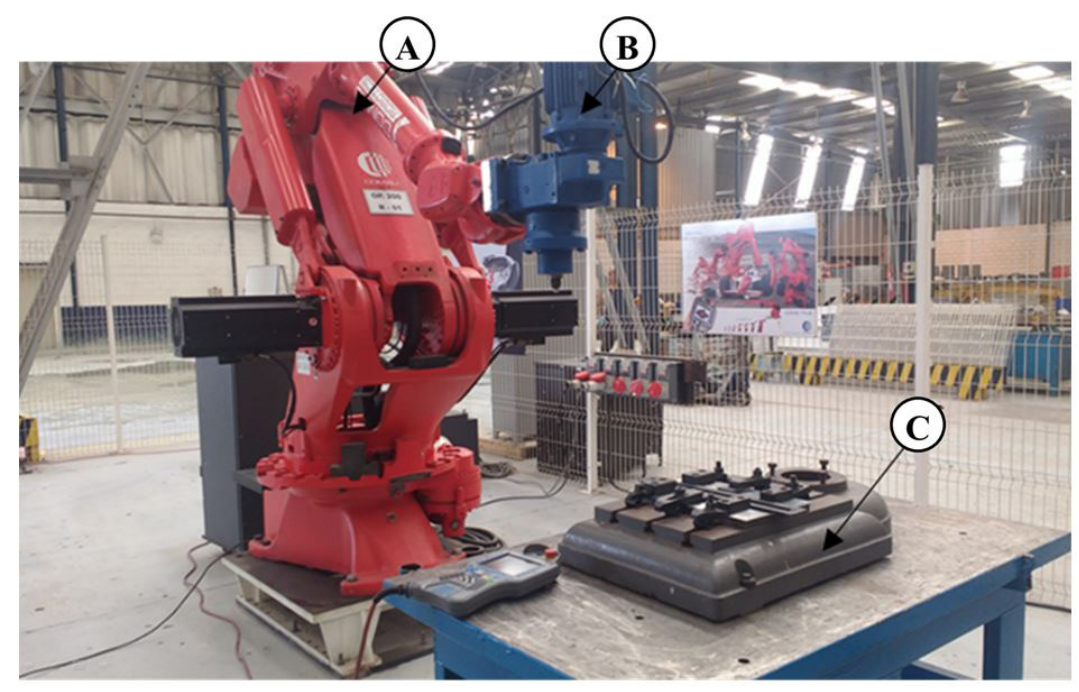

Figura 3. Montagem experimental [13]. 
Predição da Distribuição de Temperatura em Juntas da Liga de Alumínio 5052 H34 Soldadas pelo Processo Friction Stir Welding

\subsubsection{Material}

Foi utilizada a liga Al 5052 H34 de 3 mm de espessura, que possui o magnésio como principal elemento de liga, sendo considerada de excelente soldabilidade e com boa resistência à corrosão, principalmente em atmosfera salina. A série Al 5xxx possui aplicações em diferentes setores produtivos, passando por produtos que variam desde navios e embarcações, tanques de gasolina, placas de sinalização até estruturas automotivas [14].

A composição química e as propriedades mecânicas da liga Al 5052 H34 são apresentadas nas Tabelas 2 e 3, segundo ASTM B209M [15]. Verifica-se que o principal elemento da liga é o magnésio, que de forma mais efetiva que o manganês (elemento utilizado em outras séries de ligas), oferece uma resistência mecânica razoavelmente maior, caso comparada às demais ligas da série 5xxx.

Tabela 2. Limites de composição química para a liga Al 5052 (\% em peso) [15].

\begin{tabular}{cccccccccc}
\hline Al & Mg & Si & Fe & Zn & Cu & Pb & Mn & Cr \\
97,181 & 2,340 & 0,032 & 0,22 & 0,003 & 0,014 & 0,006 & 0,038 & 0,166 \\
\hline
\end{tabular}

Tabela 3. Propriedades mecânicas da liga Al 5052 H34 [15].

\begin{tabular}{|c|c|c|c|c|c|c|c|}
\hline \multirow{2}{*}{ Têmpera } & \multicolumn{2}{|c|}{$\begin{array}{c}\text { Espessura especificada } \\
{[\mathrm{mm}]}\end{array}$} & \multicolumn{2}{|c|}{$\begin{array}{c}\text { Limite de Resistência a } \\
\text { Tração [MPa] }\end{array}$} & \multicolumn{2}{|c|}{$\begin{array}{l}\text { Limite de Escoamento } \\
{[\mathrm{MPa}]}\end{array}$} & \multirow{2}{*}{$\begin{array}{c}\text { Alongamento [\%] } \\
\text { Min, em } 50 \mathrm{~mm}\end{array}$} \\
\hline & Inferior & Superior & Mínimo & Máximo & Mínimo & Máximo & \\
\hline $\mathrm{H} 34$ & 3,2 & 6,3 & 235 & 285 & 180 & - & 6 \\
\hline
\end{tabular}

\subsubsection{Parâmetros de soldagem}

O processo de soldagem por Friction Stir Welding é diretamente influenciado pelos parâmetros de entrada, sobretudo das velocidades de avanço, rotação e ângulo de inclinação da ferramenta de soldagem. Sendo assim, foram necessários testes iniciais a fim de se estabelecer uma combinação de parâmetros que propiciassem a formação de um cordão de solda com um baixo valor de rebarbas, ausência de sulcos ou vazios ao longo da linha de soldagem e penetração total visual. Assim como houve uma preocupação em utilizar parâmetros de soldagem que reduzissem as vibrações e ruídos, conforme Cota e Bracarense [16].

Os parâmetros testados e que permitiram a soldagem da liga Al 5052 H34 com 3 mm de espessura são apresentados na Tabela 4, em que verifica-se que a velocidade rotacional da ferramenta foi mantida constante em 378rpm, e a velocidade de avanço em 7,5 mm/min. A rotação foi medida experimentalmente por meio de um tacômetro digital modelo DT-2234C, com resolução de 0,1 rpm e incerteza de $\pm 0,05 \%+1$ dígito. A ferramenta sofreu uma inclinação de $2^{\circ}$. Para a verificação do ângulo, foi utilizado o medidor de inclinação digital da marca INSIZE, modelo 2178-1, com capacidade de medição $0-180^{\circ}$, resolução $0,1^{\circ}$ e incerteza de $\pm 0,1^{\circ}$, que foi fixado no cabeçote do sistema de soldagem por meio de sua base magnética. As soldas foram realizadas com sentido horário de rotação.

Tabela 4. Parâmetros finais para a soldagem da liga Al 5052 H34.

\begin{tabular}{|c|c|c|c|c|c|}
\hline $\begin{array}{c}\text { Velocidade de } \\
\text { Avanço }[\mathrm{mm} / \mathrm{min}]\end{array}$ & $\begin{array}{l}\text { Sentido de } \\
\text { Rotação }\end{array}$ & $\begin{array}{l}\text { Velocidade de } \\
\text { Rotação [rpm] }\end{array}$ & Penetração [mm] & $\begin{array}{c}\text { Ângulo de } \\
\text { Inclinação [graus] }\end{array}$ & $\begin{array}{l}\text { Tempo de } \\
\text { Espera [s] }\end{array}$ \\
\hline 7,5 & Horário & 378 & 2,9 & 2 & 20 \\
\hline
\end{tabular}

\subsubsection{Ferramenta}

As dimensões principais da ferramenta usada na soldagem da liga Al 5052 H34 com 3 mm de espessura são apresentadas na Figura 4, o pino cônico possui uma inclinação de $10^{\circ}$, o que contribui para distribuição e redução das forças envolvidas no processo durante a fase de penetração da ferramenta. Verifica-se ainda que as dimensões da ferramenta estão de acordo com as indicações de diversos autores, que recomendam que o diâmetro do pino seja próximo à espessura das chapas a serem soldadas. Além disso, o comprimento do pino deve ser um pouco 


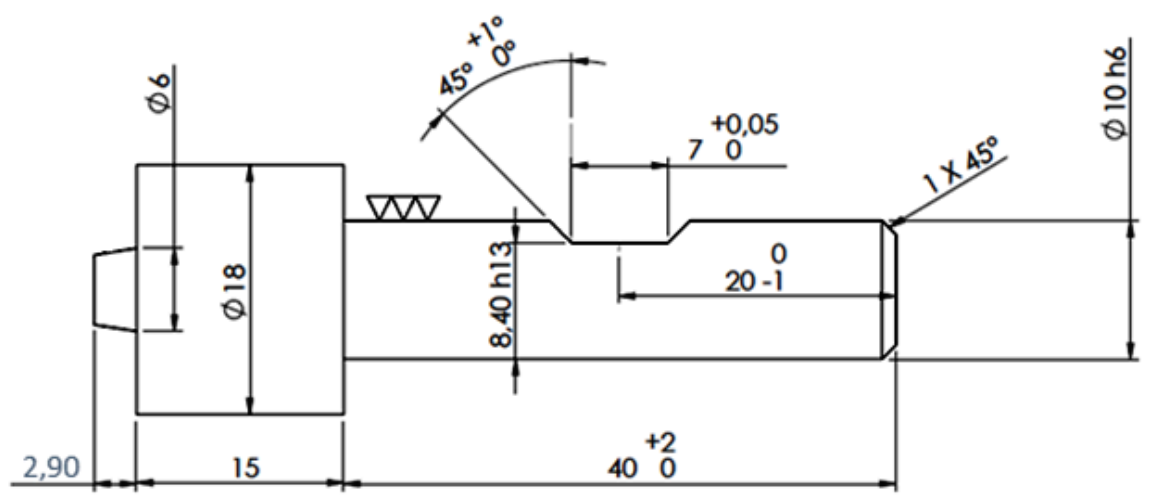

Figura 4. Dimensões principais da ferramenta usada no processo FSW para soldagem da liga Al 5052 H34 [16].

inferior a espessura da chapa a ser soldada e o diâmetro do ombro da ferramenta deve corresponder a três vezes o diâmetro maior do pino [17-21]. Foi utilizado o material AISI H13 para a fabricação das ferramentas, por ser o mais comumente aplicado na soldagem de ligas de alumínio e devido à alta resistência mecânica e boa resistência ao desgaste em temperaturas elevadas [22-24].

\subsubsection{Medidas de temperatura}

A distribuição da temperatura nas chapas de alumínio foi verificada por quatro termopares dispostos no centro da amostra, perpendiculares à linha de soldagem, conforme realizado por Zhu e Chao [25]. Foram utilizados termopares minerais blindados do tipo k, com diâmetro de $1 \mathrm{~mm}$ e comprimento de $50 \mathrm{~mm}$, revestidos com fibra e trança. Os termopares (T1, T2, T3 e T4) foram inseridos no lado de avanço e, em seguida, no lado de retrocesso das chapas por meio de furos realizados com uma broca de $1 \mathrm{~mm}$ em uma profundidade de 1,5 mm, correspondendo à metade da espessura das amostras, conforme apresentado na Figura 5. Foi realizado um cordão de solda com comprimento de $140 \mathrm{~mm}$, sendo a temperatura medida na metade do processo, em um comprimento de $70 \mathrm{~mm}$. O primeiro termopar (T1) foi posicionado a $15 \mathrm{~mm}$ da linha de soldagem e os demais (T2, T3 e T4) a 25, 35 e $45 \mathrm{~mm}$, respectivamente. Um segundo teste foi realizado com os termopares (T1, T2, T3 e T4) posicionados a 15, 20, 30 e $40 \mathrm{~mm}$ da linha de soldagem, respectivamente (Figura 5).

Para a leitura dos dados de temperatura, foi utilizado o sistema de aquisição portátil SAP 4V Ti, fabricado pelo IMC Soldagem ${ }^{\circledR}$, que possui oito canais para a aquisição de temperatura, conforme apresentado na Figura 6 . Para o

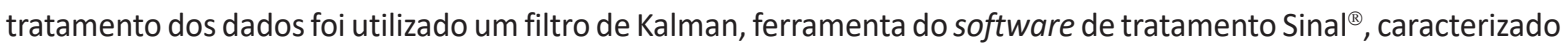
como uma ferramenta estatística eficiente por minimizar o erro quadrático, sobretudo, em séries temporais.

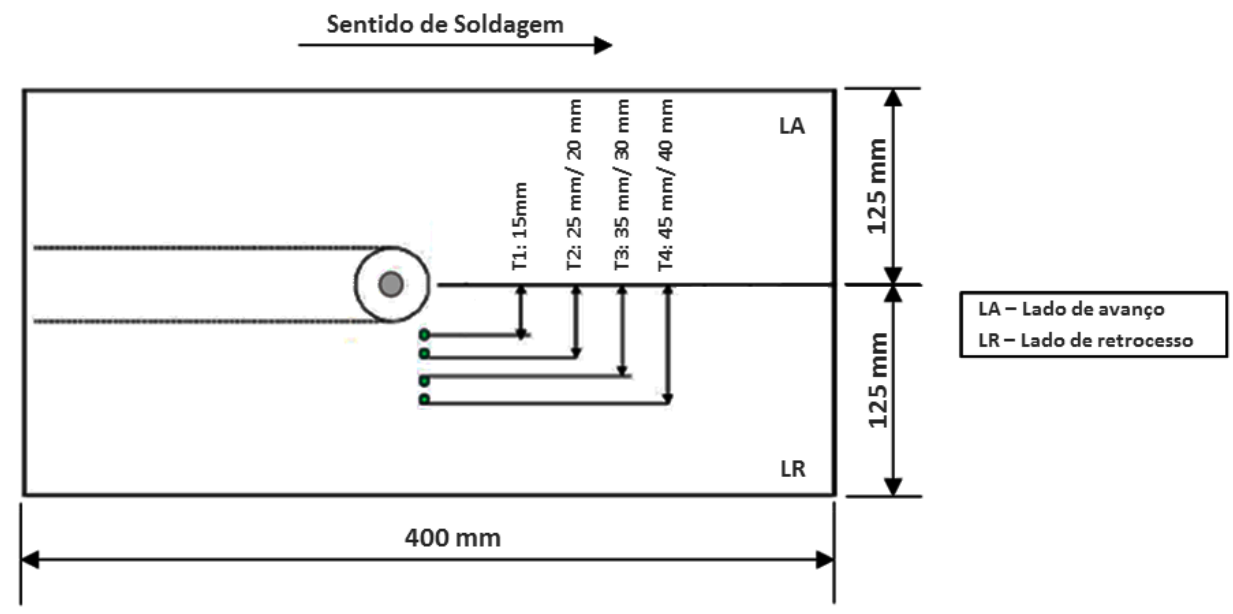

Figura 5. Montagem experimental para a aquisição da temperatura durante a soldagem [24]. 


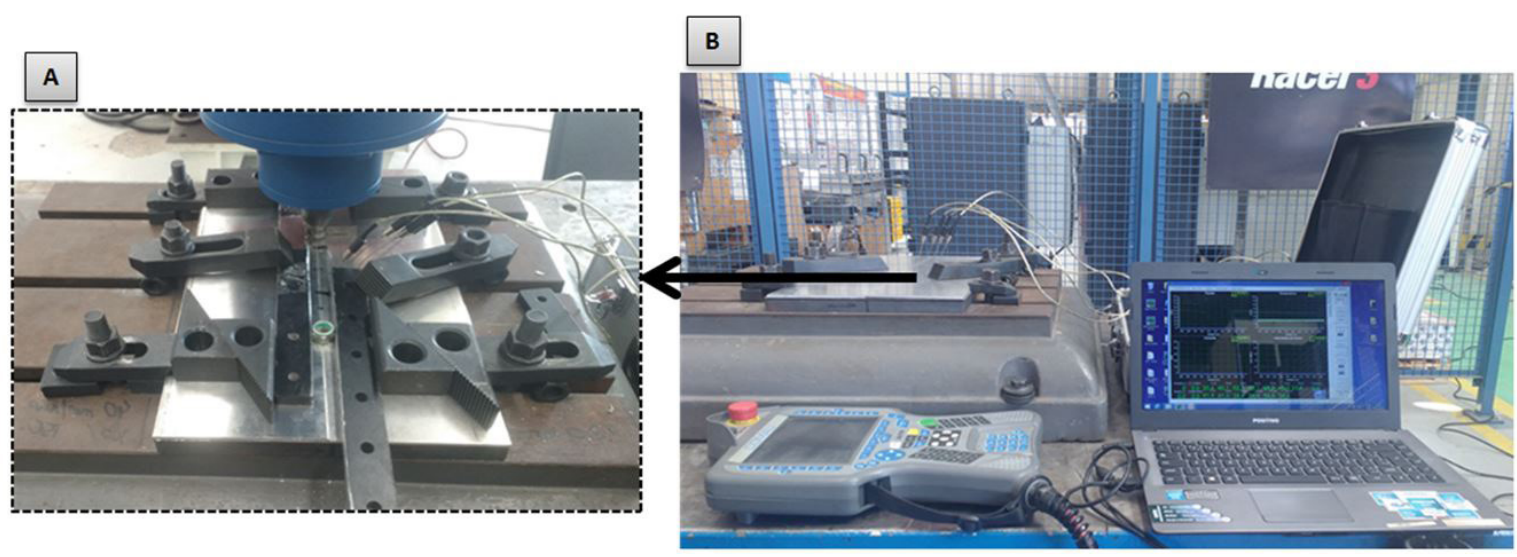

Figura 6. Posicionamento dos termopares (A) e sistema para a aquisição de dados de temperatura SAP 4V Ti (B) [24].

Os ensaios de soldagem foram realizados seguindo o modelo de experimento Fatorial Completo, especificamente o planejamento Fatorial $2 k$, considerando apenas uma réplica. Isso devida à correlação entre os fatores analisados e a restrição característica da região experimental, o que totalizou quatro ensaios realizados em ordem aleatória definida com auxílio do modo DOE - Design of Experiments. Nesse caso, a variável de resposta foi a variação de temperatura e os fatores a serem considerados foram: a mudança do lado da chapa e a variação da distância de um dos pontos a ser medido.

\section{Resultados e Discussão}

\subsection{Análise experimental da distribuição da temperatura}

A determinação da temperatura durante a soldagem pelo processo Friction Stir Welding não é uma tarefa trivial. Os perfis térmicos, geralmente medidos por termopares, são mensurados o mais próximo possível da junta de soldagem de modo a evitar colisão entre ombro da ferramenta e os instrumentos de medição. Isso se torna um problema no momento que são consideradas as fontes de variáveis operacionais, tais como: vibração, desgaste, variação no atrito e movimento relativos.

As Figuras 7 e 8 apresentam os gráficos com os resultados do experimento conforme descrito na metodologia, para os lados de avanço e retrocesso, em que os termopares (T1, T2, T3 e T4) foram posicionados a 15, 25, 35 e $45 \mathrm{~mm}$ da interface de soldagem. Observa-se um aumento na temperatura em regiões mais próximas da interface de soldagem. Fato esperado, visto que estas regiões sofrem maiores esforços, deslocamentos, fluxo de material e deformações. Consequentemente, maiores incrementos de temperatura.

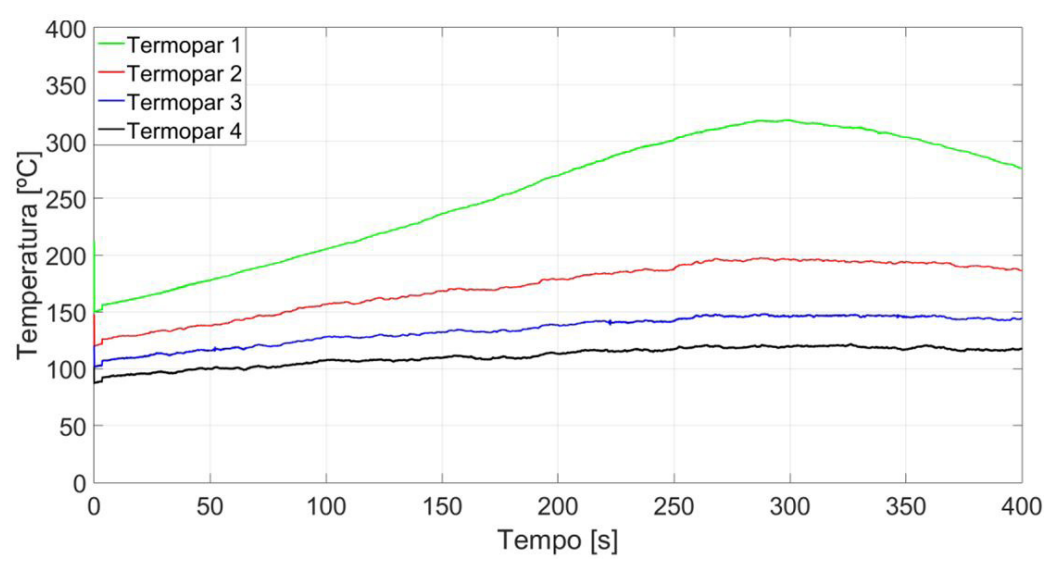

Figura 7. Perfil térmico para o lado de avanço em que os termopares (T1, T2, T3 e T4) foram posicionados a $15,25,35$ e $45 \mathrm{~mm}$ da interface de soldagem. 
Os resultados dos picos de temperatura para os termopares (T1, T2, T3 e T4) posicionados a 15, 25, 35 e $45 \mathrm{~mm}$ da interface de soldagem são apresentados na Figura 9, em que são diferenciados os lados de avanço (positivo) e retrocesso (negativo). O ponto zero indica a interface de soldagem, e as linhas tracejadas correspondem ao diâmetro do ombro da ferramenta. Esses picos constituem a denominada curva de repartição térmica, que representa a distribuição de temperatura ao longo da chapa e evidencia as regiões básicas que sofreram alguma influência ou não (ZM, ZTA e MB) durante o processo. Tal fato torna-se claro ao se observar uma diferença máxima entre a temperatura do lado de avanço e retrocesso de aproximadamente $50{ }^{\circ} \mathrm{C}(15 \%)$. Nota-se que essa diferença decai conforme os pontos de medição se distanciam do ombro, o que evidencia a influência da assimetria na distribuição de temperatura no processo de soldagem.

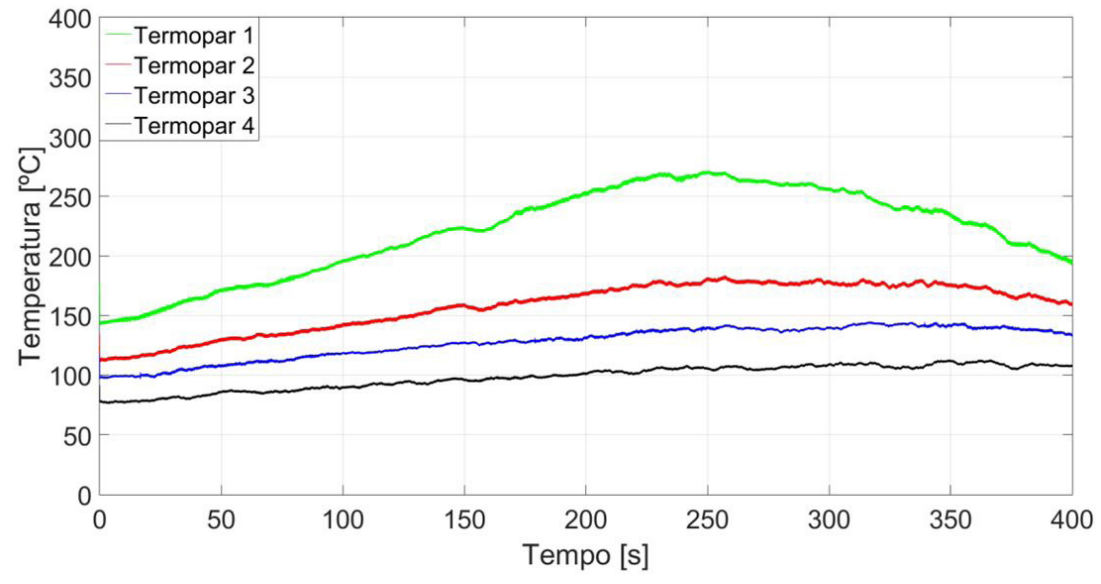

Figura 8. Perfil térmico para o lado de retrocesso em que os termopares ( $T 1, T 2, T 3$ e $T 4)$ foram posicionados a $15,25,35$ e $45 \mathrm{~mm}$ da interface de soldagem.

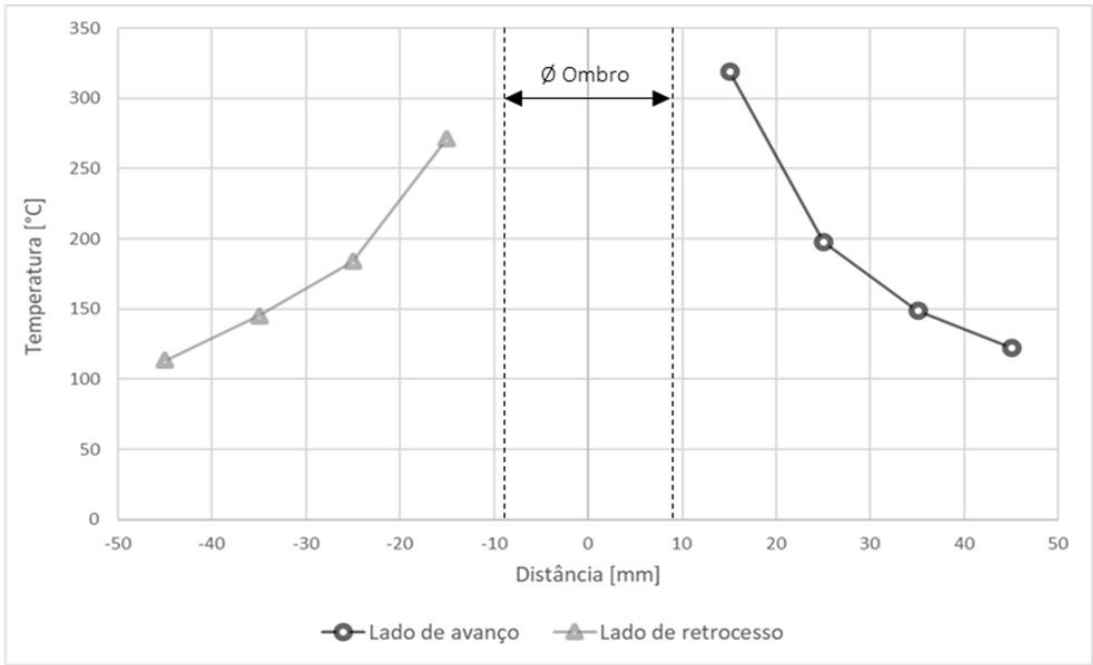

Figura 9. Picos de temperatura durante a soldagem da liga 5052 H34 em que os termopares (T1, T2, T3 e T4) foram posicionados a 15, 25, 35 e $45 \mathrm{~mm}$ da interface de soldagem.

As Figuras 10 e 11 apresentam os gráficos com os resultados do experimento conforme descrito na metodologia, para os lados de avanço e retrocesso, em que os termopares (T1, T2, T3 e T4) foram posicionados a 15, 25, 35 e $45 \mathrm{~mm}$ da interface de soldagem. Para o caso dos testes apresentado, a única diferença para a primeira configuração é a disposição dos furos na chapa. Dessa forma, todas as considerações para o comportamento esperado para os lados de avanço e retrocesso também valem para este caso. Na prática, isso faz com que se tenham variações na temperatura tanto para diferentes profundidades quanto para diferentes lados. 
Predição da Distribuição de Temperatura em Juntas da Liga de Alumínio 5052 H34 Soldadas pelo Processo Friction Stir Welding

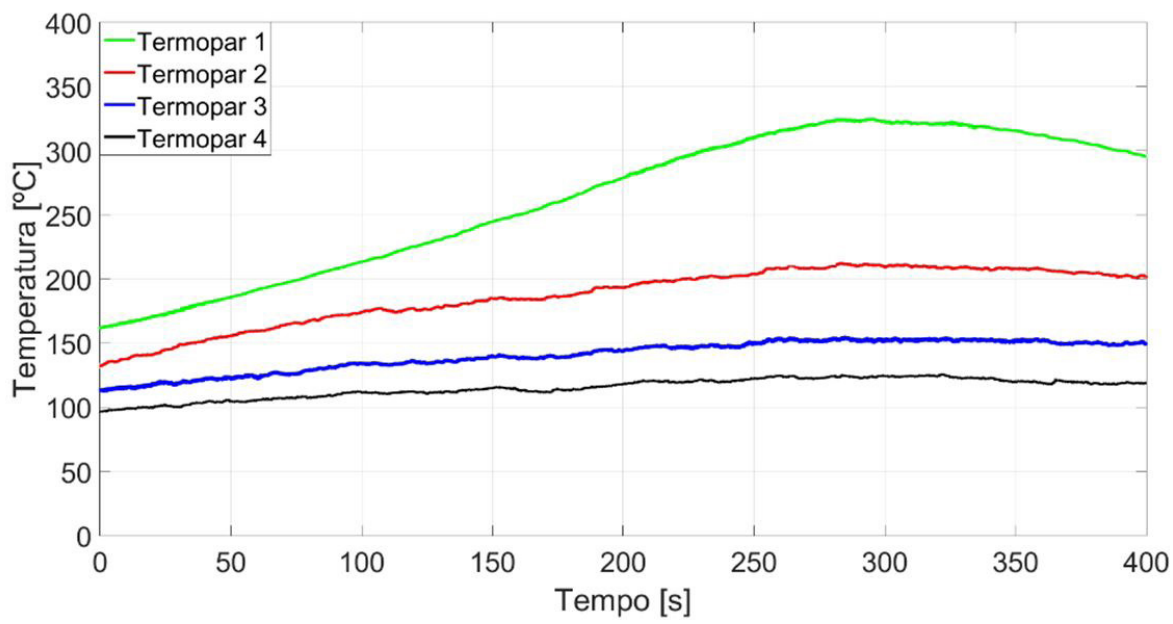

Figura 10. Perfil térmico para o lado de avanço em que os termopares (T1, T2, T3 e T4) foram posicionados a 15, 20, 30 e $40 \mathrm{~mm}$ da interface de soldagem.

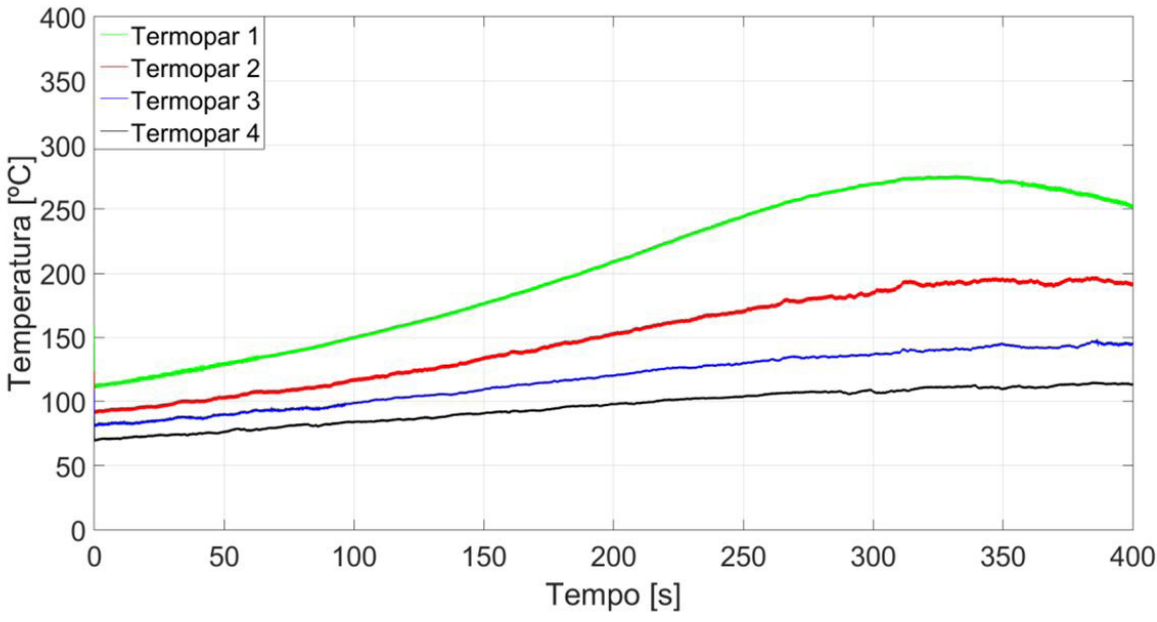

Figura 11. Perfil térmico para o lado de retrocesso em que os termopares (T1, T2, T3 e T4) foram posicionados a 15, 20, 30 e $40 \mathrm{~mm}$ da interface de soldagem.

Os resultados dos picos de temperatura para os termopares (T1, T2, T3 e T4) posicionados a 15, 20, 30 e $40 \mathrm{~mm}$ da interface de soldagem são apresentados na Figura 12, em que são diferenciados os lados de avanço (positivo) e retrocesso (negativo). Novamente, o ponto zero indica a interface de soldagem, e as linhas tracejadas correspondem ao diâmetro do ombro da ferramenta. Com base em análise dos dados apresentados, novamente, nota-se os mesmos $15 \%$ de diferença na temperatura dos lados de avanço e retrocesso, para o ponto máximo. Segundo Rajesh et al. [10], essa diferença ocorre devido à assimetria na plasticidade do material e a forma com que este se movimenta durante o processo de soldagem. A rotação da ferramenta, combinada à velocidade de avanço faz com que as forças se distribuam de maneira desigual, o que altera a forma que o calor é gerado no interior da peça.

Os valores encontrados nos ensaios estão equivalentes aos resultados encontrados por diversos pesquisadores que verificaram tanto virtualmente quanto experimentalmente a distribuição de temperatura durante o processo [26-28]. Tang et al. [29] fez um levantamento para a NASA (National Aeronautics and Space Administration), em que foram identificadas experimentalmente as temperaturas durante a soldagem de chapas de alumínio, variando-se diversos parâmetros. O autor encontrou picos de temperatura na faixa de $450^{\circ} \mathrm{C}$ na linha de soldagem e temperaturas na faixa de $300^{\circ} \mathrm{C}$ a $16 \mathrm{~mm}$ da linha de soldagem. 


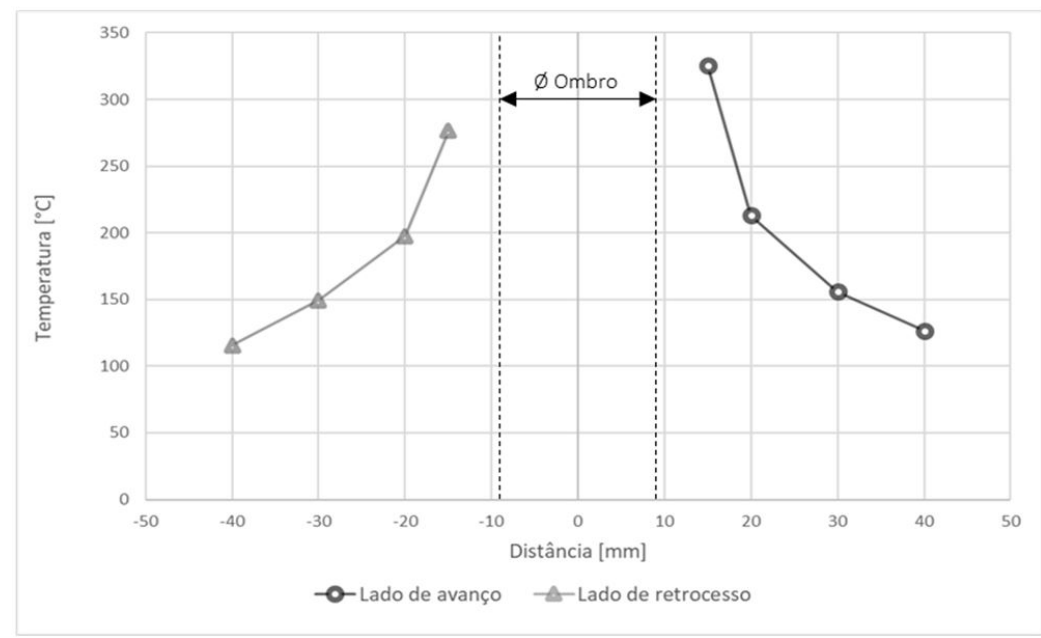

Figura 12. Picos de temperatura durante a soldagem da liga 5052 H34 em que os termopares (T1, T2, T3 e T4) foram posicionados a 15, 20, 30 e $40 \mathrm{~mm}$ da interface de soldagem.

A amostra soldada com os termopares (T1, T2, T3 e T4) posicionados no lado do avanço a 15, 20, 30 e $40 \mathrm{~mm}$ da interface de soldagem é apresentada na Figura 13. Verifica-se a presença de rebarbas (flash), depositadas no lado de retrocesso das chapas, assim como observado por outros autores [22, 23, 30].

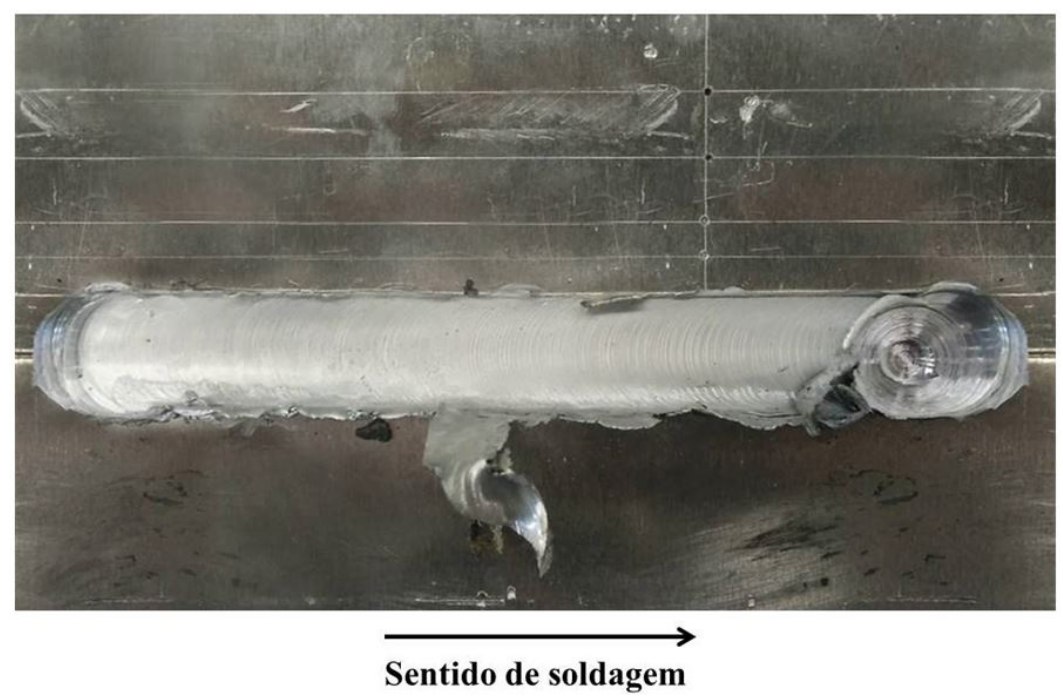

Figura 13. Amostra soldada com os termopares (T1, T2, T3 e T4) posicionados no lado de avanço a 15, 20, 30 e $40 \mathrm{~mm}$ da interface de soldagem.

A influência do perfil da ferramenta na qualidade da junta soldada pode ser verificada medindo-se as propriedades mecânicas da junção por meio da realização de testes, o que não foi feito durante os experimentos narrados neste trabalho. A qualidade da solda e a sua aceitabilidade foram testadas conforme parâmetros visuais básicos de qualidade, como por exemplo, o aspecto da solda, baixo nível de rebarbas, ausência de defeitos superficiais ao longo da junta soldada e penetração total visível que podem ser observados em Figura 13.

\subsubsection{Análise combinada das curvas de repartição térmica}

Como os gráficos foram obtidos em experimentos e em pontos distintos, foi testada a hipótese de juntá-los com base na análise do desvio padrão dos pontos medidos em posições similares. Estrategicamente, o primeiro ponto de medição foi mantido constante nos quatro testes, $15 \mathrm{~mm}$ do ombro da ferramenta, tanto no lado de 
Predição da Distribuição de Temperatura em Juntas da Liga de Alumínio 5052 H34 Soldadas pelo Processo Friction Stir Welding

avanço quanto no de retrocesso. Assim, o ponto em questão foi adotado como referencial de compatibilidade por estar mais próximo da ferramenta e sujeito a maiores alterações nos dados medidos durante o processo, devido, sobretudo, às vibrações.

Os dados apresentados na Tabela 5 descrevem o primeiro ponto de medição (T1) que, conforme detalhado na metodologia foi mantido a $15 \mathrm{~mm}$ da linha de soldagem em todos os testes. O valor encontrado para o desvio padrão, que nesse caso é apenas a metade da diferença, por se tratar apenas de duas medições, foi de no máximo 3,13 . Esse desvio corresponde a menos de $1 \%$ de variação, dada à ordem de grandeza das temperaturas. No caso da diferença simples percentual entre os pontos, esse valor é inferior a $2 \%$. Dessa forma, unir as duas medições em um único gráfico foi considerado como aceitável estatisticamente.

Tabela 5. Análise da temperatura no termopar T1 nos gráficos de repartição térmica.

\begin{tabular}{ccccc}
\hline & Teste 1-2 & Teste 3-4 & Desvio Padrão & Diferença [\%] \\
Lado de Avanço & 319,41 & 325,67 & 3,13 & 1,92 \\
Lado de Retrocesso & 271,44 & 276,41 & 2,50 & 1,80 \\
\hline
\end{tabular}

Ao combinar os dois gráficos, é possível avaliar um maior número de parâmetros estatísticos no intuito de validar a hipótese inicial de aglutinação. Um deles é equacionar um modelo de curva que passe pela maioria dos pontos respeitando o formato previsto em literatura. Neste caso, os modelos que mais se assemelhariam aos teóricos seriam os de equações do segundo grau e exponenciais. No entanto, a exponencial não pode ser usada para representar a parte negativa de gráficos, por incompatibilidade matemática. Sendo assim, foi adotada a primeira opção, em que os valores dos coeficientes da equação estão descritos no gráfico apresentado na Figura 14.

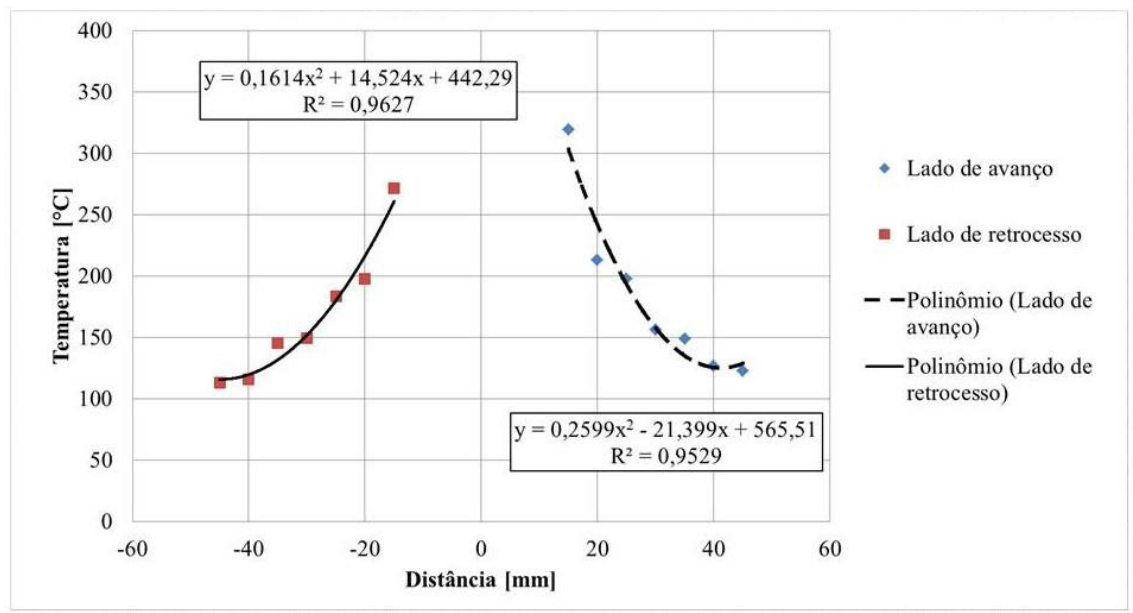

Figura 14. Repartição térmica dos testes.

O fator mais relevante apresentado é o coeficiente de determinação (R2), que mede o ajuste de um modelo estatístico aos pontos que o geraram. Nota-se que o menor valor observado para o coeficiente, em ambas as curvas ajustadas, é de 0,9529. Tal valor indica um ajuste aceitável para um modelo estatístico linear generalizado, pois de acordo com Wallace [31], o valor de $\mathrm{R}^{2}$ é considerado ótimo quando próximo de 1.

\subsection{Análise virtual da distribuição da temperatura}

Conforme detalhado na metodologia, foi realizada uma análise em elementos finitos utilizando solver HyperXtrude ${ }^{\circledR}$ para uma chapa de Al $5052 \mathrm{com} 3 \mathrm{~mm}$ de espessura. Foi observado que a curva de repartição térmica apresenta valores próximos ao medido fisicamente se adicionado um fluxo de saída, na base, de $3000 \mathrm{~W} / \mathrm{m}^{2}$. Os valores obtidos nas diferentes zonas de soldagem são apresentados na Figura 15, ressaltando que foi obtida 
$-512.84$

$-451.86$

$-390.88$

$-329.90$

$-268.92$

$-207.94$

$-146.96$

$-85.98$

25.00

- No result

$\operatorname{Max}=573.82$

Nodes 3359

Min $=25.00$

Nodes 126

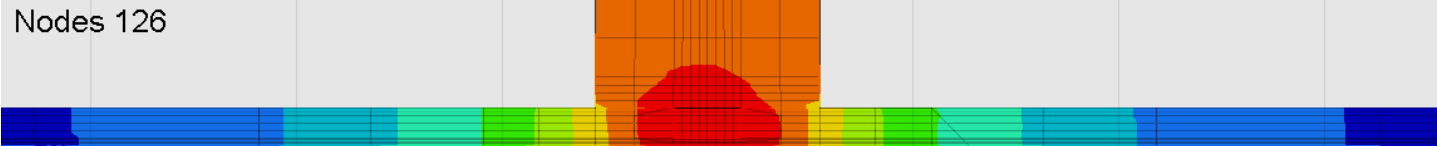

Figura 15. Distribuição de temperatura virtual para a liga de alumínio 5052 durante a soldagem pelo processo Friction Stir Welding.

uma temperatura máxima de 573 ㄷ C para as proximidades da região de contato entre o pino e substrato. Outro ponto a ser considerado é a distorção na área de maior temperatura "nugget", característica do processo.

A teoria sobre esta distorção está relacionada com a forma com que o fluxo de material se comporta na região soldada durante o processo. Na prática, isso faz com que surjam diferentes zonas de deformação devido a fatores geométricos da ferramenta, combinados ao seu giro, translação e à movimentação complexa do material. O que causa diferentes gradientes de deformação, temperatura e de taxa de deformação. Dessa forma, como o lado de avanço apresenta maiores valores de deformações, têm-se como consequência as diferentes temperaturas para os lados de avanço e retrocesso, conforme estudos realizados por Rajesh et al. [10]. O contorno da temperatura após a simulação de soldagem é apresentado na Figura 16.
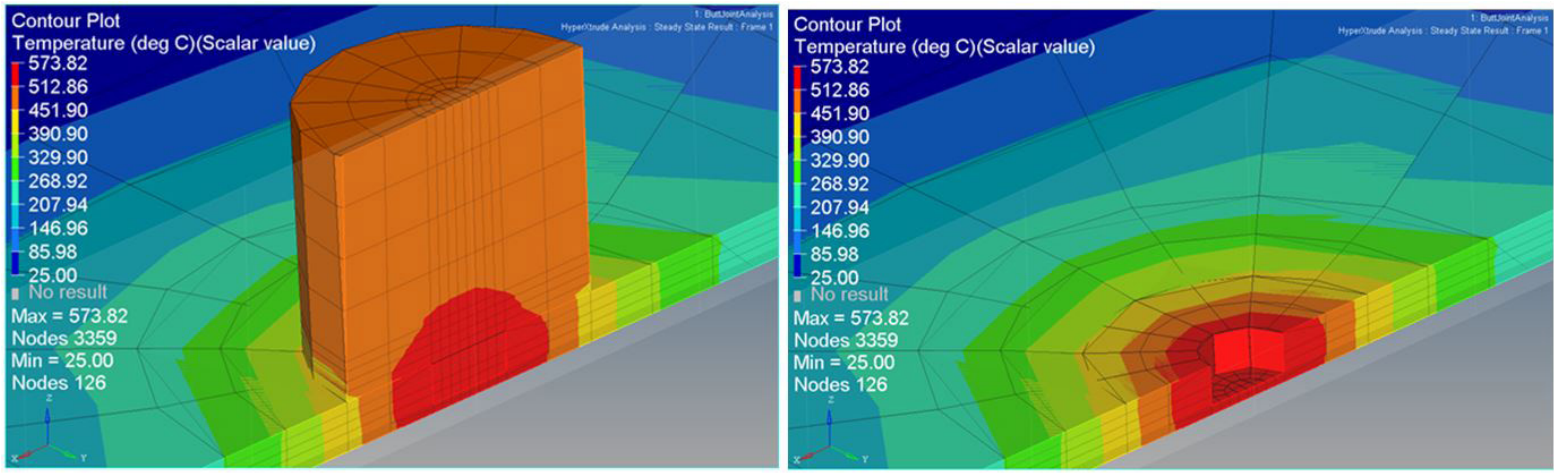

Figura 16. Contorno da temperatura após a simulação da soldagem pelo processo Friction Stir Welding da liga de alumínio 5052.

Um dos recursos do HyperExtrude ${ }^{\circledR}$ é o cálculo das temperaturas máximas para qualquer ponto escolhido no perfil soldado, Node Path. Dessa forma, traçando-se uma reta no centro da peça é possível observar o perfil térmico para o comprimento escolhido. O caminho nodal e a curva gerada em software podem ser observados na Figura 17.

Com base nessa ferramenta, é possível selecionar uma quantidade razoável de pontos e gerar a curva de repartição térmica para o modelo do Altair ${ }^{\circledR}$ correspondente aos experimentos realizados, conforme apresentado na Figura 18. Na curva de repartição térmica é possível observar o mesmo fenômeno experimental, onde nota-se 
Predição da Distribuição de Temperatura em Juntas da Liga de Alumínio 5052 H34 Soldadas pelo Processo Friction Stir Welding

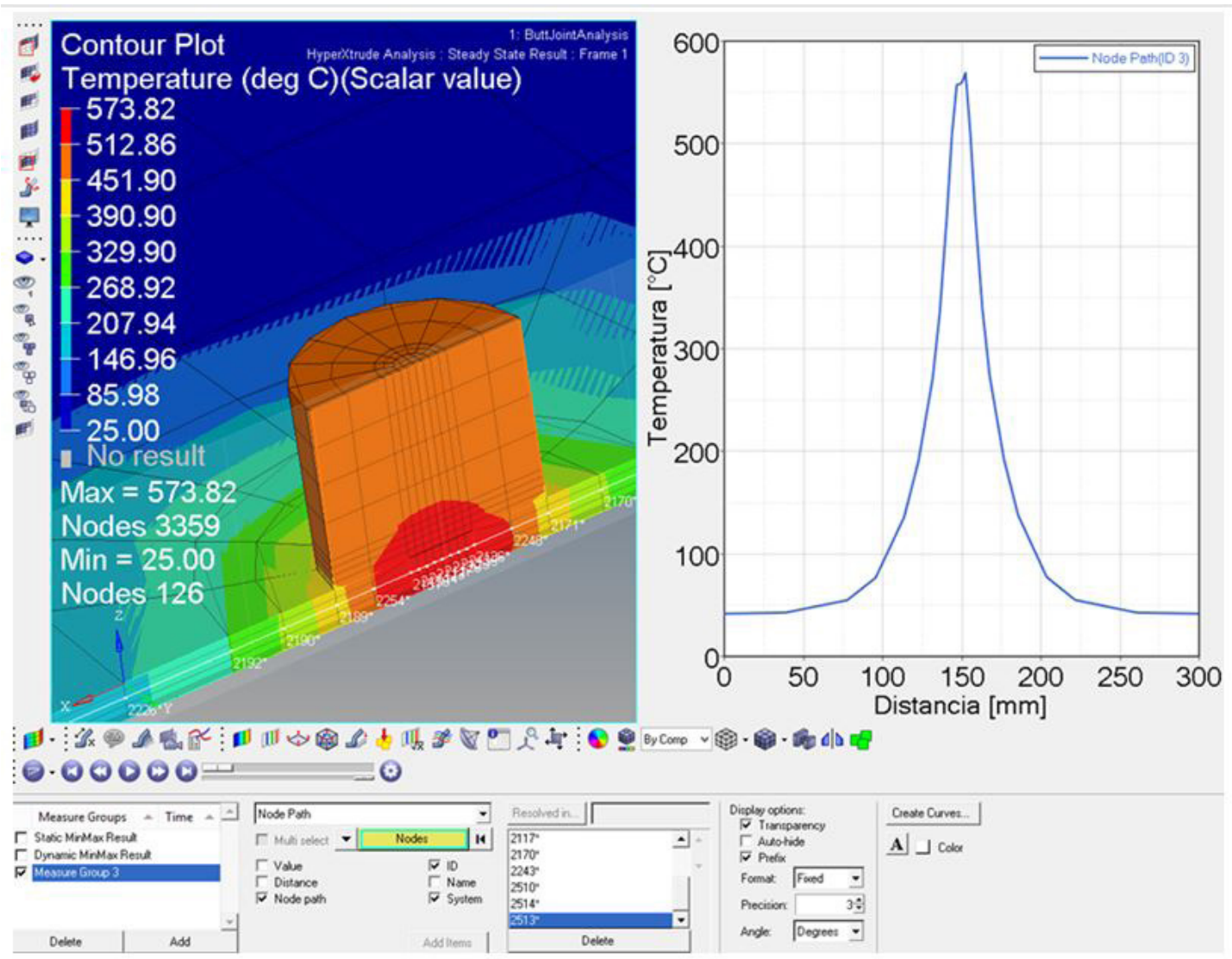

Figura 17. Recurso "Node Path" do software Altair ${ }^{\circledR}$.

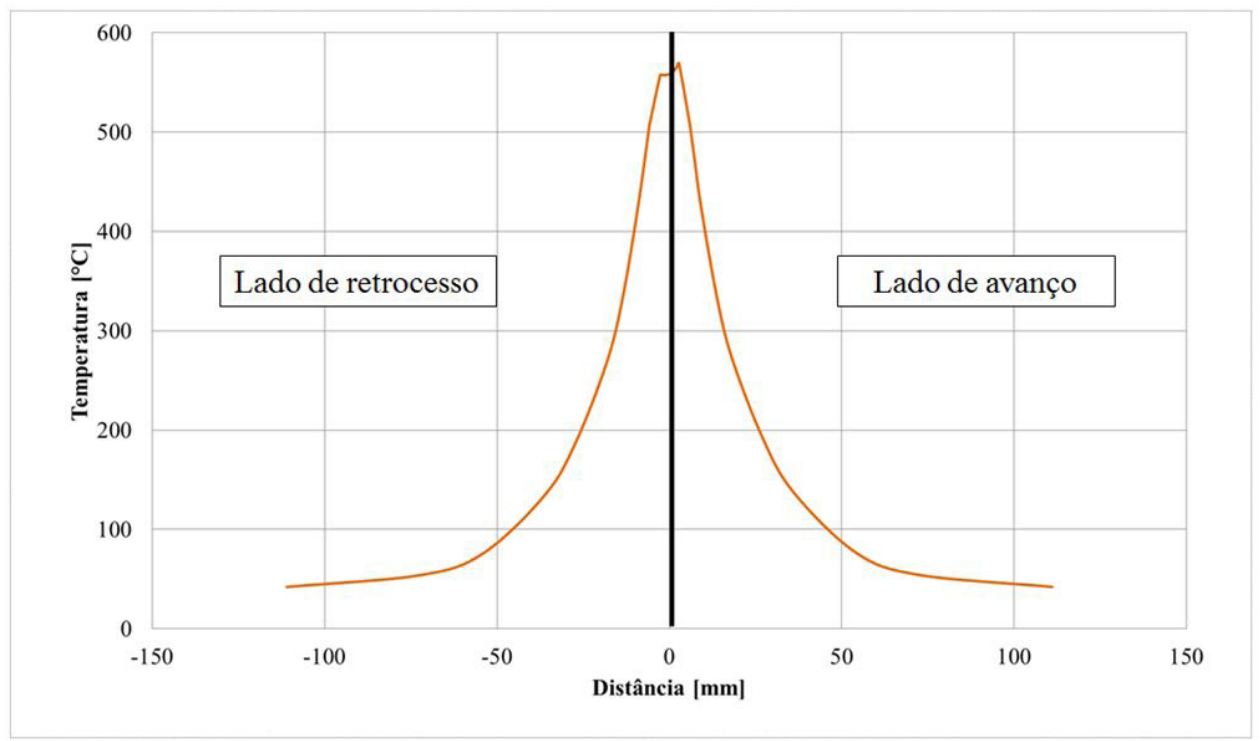

Figura 18. Curva de repartição térmica gerada pelo modelo do software Altair ${ }^{\circledR}$.

uma inflexão na curva de temperatura indicando que de fato existe uma diferença entre a temperatura dos lados de avanço e retrocesso. Outro aspecto que pode ser observado é a proximidade da curva encontrada pelo modelo em software com aquela obtida experimentalmente. 


\subsection{Correlação virtual físico}

Durante o processo de soldagem, a junta é criada através do calor gerado pela fricção entre a ferramenta e a chapa. O material atinge o regime plástico, sofre mistura e extrusão devido ao movimento de uma ferramenta rotativa. $O$ entendimento da geração de calor e do histórico de temperatura durante o processo de soldagem é o primeiro passo para entender o processo termomecânico que a junta está sujeita. Assim, ter um modelo matemático que realiza a comparação entre o virtual e o físico de forma confiável gera uma economia de tempo e recursos dispendidos em uma possível tratativa experimental.

Uma das variáveis do processo de soldagem por FSW é a velocidade de rotação da ferramenta. O fato da velocidade aumentar faz com que se aumente também a quantidade de calor gerado durante o processo. Dessa forma para entender como uma variável, no caso a velocidade de rotação da ferramenta, atua na geração de calor originaria uma série de experimentos, pelo menos um para cada uma das velocidades estudadas. Isso sem considerar os demais parâmetros envolvidos no processo, como geometria da peça e da ferramenta, propriedades do material, ângulo de inclinação da ferramenta, alteração nas condições iniciais, dentre outras.

A comparação entre as temperaturas previstas no modelo virtual e nos estudos experimentais está apresentada na Figura 19.

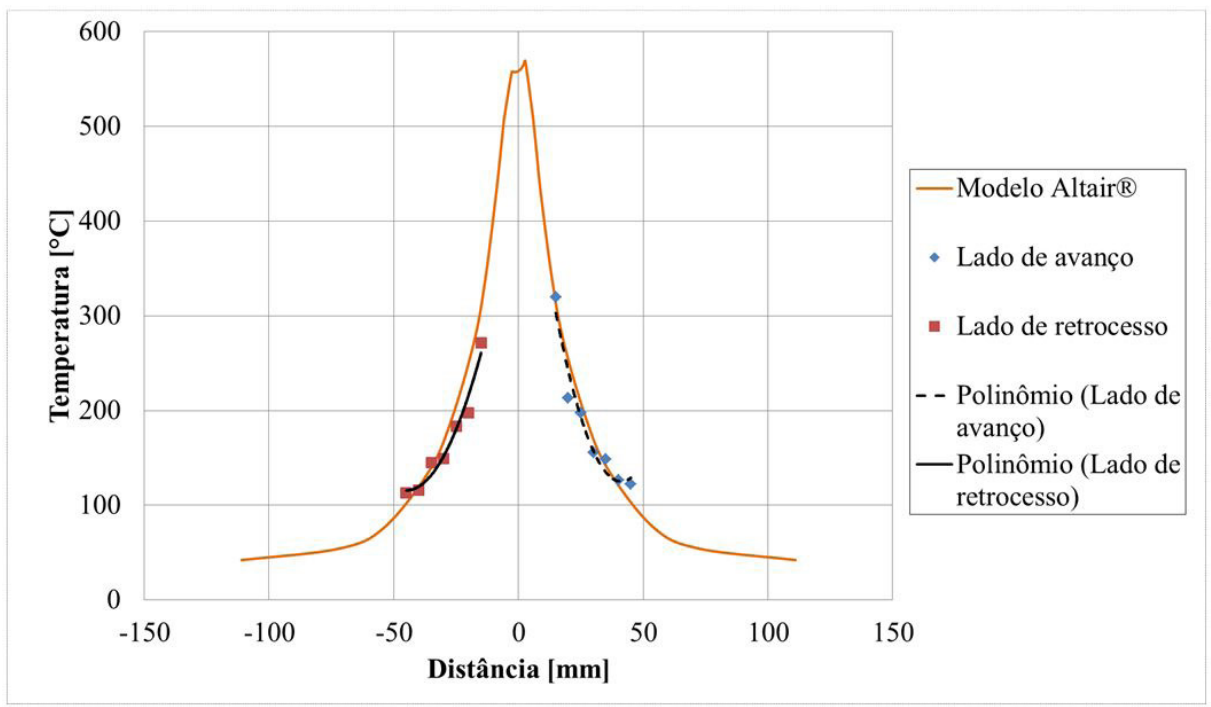

Figura 19. Correlação virtual-física para as curvas de repartição térmica.

O coeficiente de determinação $\left(R^{2}\right)$ pode ser obtido para cada um dos lados da curva apresentada na Figura 19. Esse coeficiente, conforme já mencionado anteriormente, mede o ajuste de um modelo estatístico aos pontos que o geraram. Entretanto, nesse caso, o que será medido é o nível de ajuste entre os pontos obtidos experimentalmente nos ensaios e aqueles advindos do modelo em software. Para tanto, foram analisados os lados de avanço e retrocesso separadamente, conforme apresentado na Figura 20. Dessa forma, foram calculados os valores de 0,9311 e 0,9546 para o coeficiente $R^{2}$ nos lados de avanço e retrocesso, respectivamente.

Uma vez que se tem um modelo ajustado em software, pode-se predizer o comportamento das repartições térmicas para todos os parâmetros que influem na soldagem por FSW. Um exemplo dessa variação de parâmetros pode ser observada na Figura 21, em que foram testadas diferentes velocidades de rotação da ferramenta e mantida as demais condições físicas nos valores já mencionados ao longo deste trabalho. Dessa forma, dentro dos limites da condição de contato ferramenta/material modelados, o modelo virtual permite a predição do efeito dos parâmetros de processo na temperatura.

Existem inúmeros aspectos que podem ser observados com a predição dos valores de temperatura, sendo que o mais importante dos pontos é o econômico, uma vez que em minutos é possível predizer as variáveis de saída do experimento. Isso em um experimento convencional teria um custo não só do tempo para a predição como também um gasto material, uma vez que parte dos recursos é consumível. 
Predição da Distribuição de Temperatura em Juntas da Liga de Alumínio 5052 H34 Soldadas pelo Processo

\section{A}

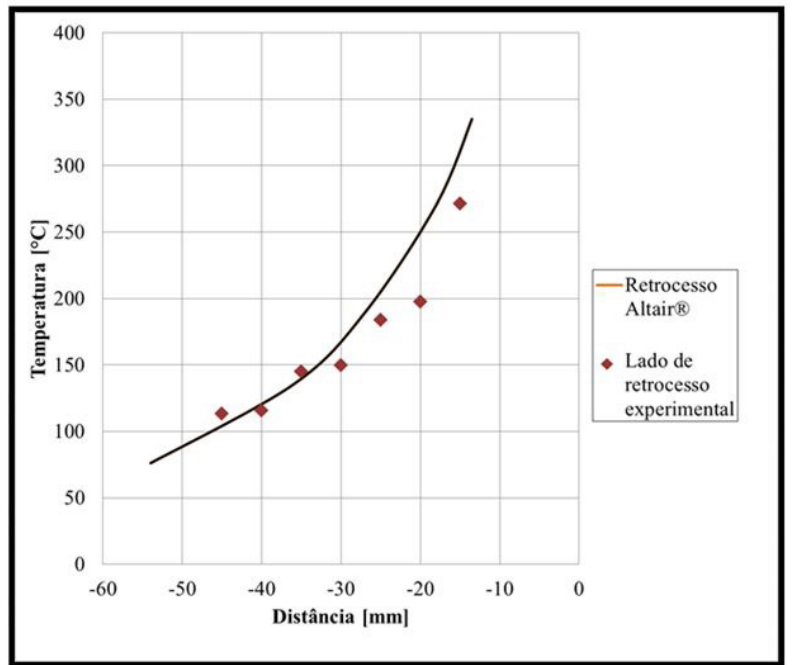

B

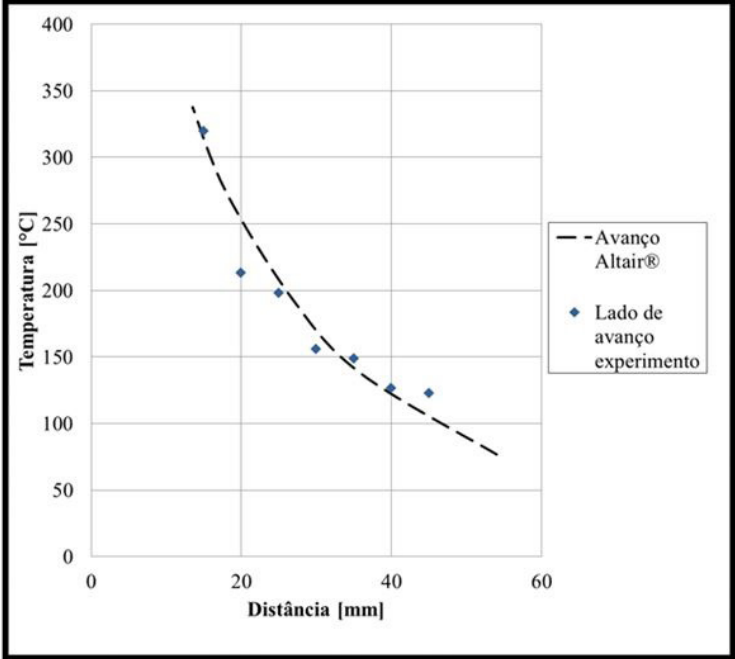

Figura 20. Curvas utilizadas para a análise do ajuste: (A) Lado de retrocesso; (B) Lado de avanço.

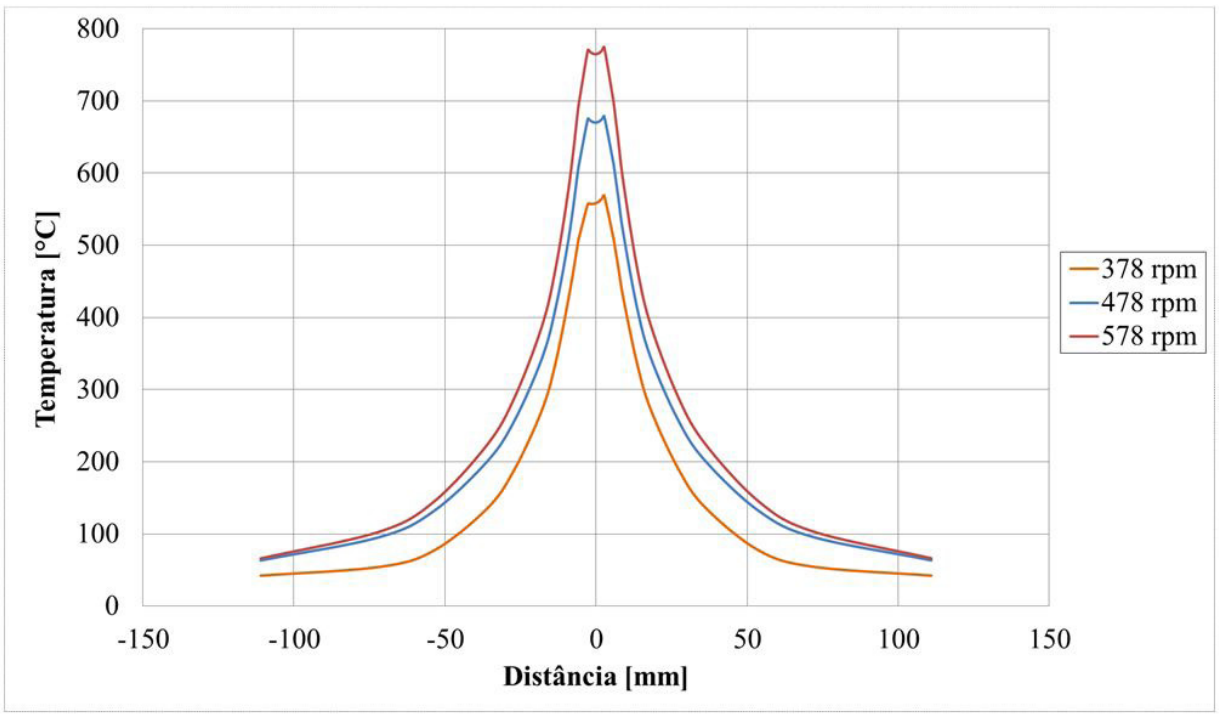

Figura 21. Predição dos valores de temperatura para diferentes rotações.

Para o resultado apresentado na Figura 21, verifica-se, na velocidade da ferramenta de $578 \mathrm{rpm}$, uma temperatura máxima de $771{ }^{\circ} \mathrm{C}$, valor que está acima do ponto de fusão do alumínio 5052 . Dessa forma, esses parâmetros combinados fazem com que o processo FSW perca sua característica fundamental de ocorrer no estado sólido. Além disso, temperaturas elevadas induzem a alterações microestruturais indesejáveis aos materiais.

Os outros pontos estão relacionados com a otimização do processo e a velocidade de produção, uma vez que para uma possível aplicação industrial é interessante que se tenha um menor gasto energético para realizar a soldagem. A exemplo de uma maior taxa de produtividade, que pode ser atingida com o aumento da velocidade de avanço da ferramenta de soldagem.

\section{Conclusões}

A partir dos resultados e discussões apresentadas neste trabalho, serão apresentadas a seguir as principais conclusões: 
1.O modelo em software do processo FSW para a liga de alumínio $5052 \mathrm{H} 34$ foi implementado utilizando o software Hyperworks Altair ${ }^{\circledR}$ e a magnitude de seus resultados foram ajustados com base nas curvas de perfis térmicos obtidos experimentalmente. Devido ao comportamento característico e análise do coeficiente de correlação, pôde-se concluir que o modelo ajustado foi capaz de predizer a distribuição de temperatura para a junta e a ferramenta de soldagem. Dessa forma, uma vez tendo realizado o ajuste, é possível extrapolar os parâmetros de entrada do modelo, como foi feito para a velocidade de rotação da ferramenta;

2. Foi observada a relação sensível dos valores de temperatura das repartições térmicas para diferentes valores de velocidade de rotação do ombro, o que está de acordo com os trabalhos de outros pesquisadores;

3. A assimetria na distribuição de temperatura entre os lados de avanço e retrocesso, observada durante os testes experimentais, foi identificada também na análise virtual, o que comprovou a influência da rotação na forma com que o material se movimenta na região soldada. Assim como o fato de que os gradientes de deformação e, consequentemente, de distribuição de temperatura fazem com que o lado de avanço apresente módulos de temperatura mais elevados;

4.O processo FSW ocorre quando a temperatura da área de soldagem atinge um valor abaixo do ponto de fusão do material da junta, porém, o suficiente para que o material entre em estado plástico e, com ajuda do ferramental, mescle ambos os lados durante a união. Dessa forma, é necessário um elevado número de testes para que seja encontrada uma combinação de parâmetros que proporcione uma solda não só factível, mas viável economicamente. O que representa a principal vantagem em se ter um modelo matemático, uma vez que é possível economizar o tempo e os recursos que seriam necessários para se determinar os perfis das repartições térmicas experimentalmente.

\section{Agradecimentos}

Ao LRSS (Laboratório de Robótica Soldagem e Simulação) da UFMG e à CAPES (Coordenação de Aperfeiçoamento de Pessoal de Nível Superior), pelo apoio e investimento à pesquisa. À COMAU do Brasil pela parceria e empréstimo do robô SMART NJ500, indispensável à essa pesquisa. A empresa Geremia Redutores, pelo apoio à pesquisa por meio da doação do redutor GD49, destinado à adaptação ao sistema de soldagem. Ao CEFET-MG, por ter cedido as máquinas para a fabricação das ferramentas de soldagem.

\section{Referências}

[1] Thomas WM, Nicholas ED, Needham JC, Murch MG, TempleSmith P, Dawes CJ. inventores; International Patent Application, cessionário. Friction stir butt welding. United Kingdom patent UK PCT/GB92/02203. 1991.

[2] Hamza E. A review of using computational fluid dynamic in simulating of friction stir welding and parametric studies. In: Proceedings of the 11th International Symposium on FSW (11ISFSW), 2016 May 17-19, Cambridge, United Kingdom. Cambridge: TWI Ltd., 2016.

[3] HeX, Gu F, Ball A. A review of numerical analysis of friction stir welding. Progress in Materials Science. 2014;65:1-66. http:// dx.doi.org/10.1016/j.pmatsci.2014.03.003.

[4] Mishra RS, Ma ZY. Friction stir welding and processing. Materials Science and Engineering R Reports. 2005;50(1):1-78. http:// dx.doi.org/10.1016/j.mser.2005.07.001.

[5] Colegrove P. 3 dimensional flow and thermal modelling of the friction stir welding process [tese de doutorado]. Austrália: Department of Mechanical Engineering, University of Adelaide; 2002.

[6] Schmidt H, Hattel J, Wert J. An analytical model for the heat generation in friction stir welding. Modelling and Simulation in Materials Science and Engineering. 2003;12(1):143-157. http:// dx.doi.org/10.1088/0965-0393/12/1/013.
[7] Armansyah, Almanar IP, Saiful Bahari Shaari M, Shamil Jaffarullah M, Nur'amirah Busu, Arif Fadzleen Zainal Abidin M, Amlie A. Kasim M. Temperature distribution in friction stir welding using finite element method. International Journal of Mechanical and Mechatronics Engineering. 2014;8(10):1699-1704.

[8] Frigaard $\varnothing$, Grong $\varnothing$, Midling OT. A process model for friction stir welding of age hardening aluminum alloys. Metallurgical and Materials Transactions. A, Physical Metallurgy and Materials Science. 2001;32(5):1189-1200. http://dx.doi.org/10.1007/ s11661-001-0128-4.

[9] Mimouni O, Badji R, Hadji M, Kouadr-Davidi A, Rachid H, Chekroun N. Numerical simulation of temperature distribution and material flow during friction stir welding 2017A aluminum alloys. MATEC Web of Conferences. 2016;80:12002. https:// doi.org/10.1051/matecconf/20168012002.

[10] Rajesh SR, Bang HS, Kim HJ, Bang HS. Analysis of complex heat flow phenomena with friction stir welding using $3 \mathrm{D}$-analytical model. Advanced Materials Research. 2007;15-17, 339-344.

[11] Patil S, Lomte S, Gogte CL. Thermal analysis of friction stir welded joint of age hardenable AA 7075 using Altair's HyperWeld FSW. USA: HTC; 2012.

[12] Yatapu YR, Reddy BR, Ramaraju RV, Ku MFBC, Ibrahim AB. Prediction of temeperatures during friction stir welding of AA6061 aluminium alloy using hyperworks. Journal of Engineering 
Predição da Distribuição de Temperatura em Juntas da Liga de Alumínio 5052 H34 Soldadas pelo Processo Friction Stir Welding

and Applied Sciences (Asian Research Publishing Network). 2016;11(18):11003-11008.

[13] Cota BS, Bracarense AQ, Coelho FGF. Sizing of a robot system for joining by friction stir welding process. Soldagem e Inspeção. 2017;22(4):480-493. http://dx.doi.org/10.1590/0104-9224/ si2204.07.

[14] Associação Brasileira de Normas Técnicas. ABNT NBR 6835: alumínio e suas ligas - classificação das têmperas. Rio de Janeiro: ABNT; 2006.

[15] American Society for Testing and Materials. ASTM B209M: standard specification for aluminum and aluminum-alloy sheet and plate. West Conshohocken: ASTM; 2001.

[16] Cota BS, Bracarense AQ. Validation of a newly developed robotic system for friction stir welding process by joining and characterizing joints of aluminum alloy 5052 H34. Soldagem e Inspeção. 2017

[17] Capelari TV, Mazzaferro JAE. Avaliação da geometria de ferramenta e parâmetros do processo FSW na soldagem da liga de alumínio AA 5052 [tese de doutorado]. Porto Alegre: Universidade Federal do Rio Grande do Sul; 2006.

[18] Colligan K. Material flow behavior during friction welding of aluminum. Welding Journal. 1999;75(7):229s-237s.

[19] Guerra M, Schmidt C, McClure JC, Murr LE, Nunes AC. Flow patterns during friction stir welding. Materials Characterization. 2002;49(2):95-101. http://dx.doi.org/10.1016/S10445803(02)00362-5.

[20] Thomas WM. Friction stir welding tool and method. United Kingdon patent UK GB 2306366. 1996.

[21] Zhao Y-H, Lin S, Wu L, Qu F. The influence of pin geometry on bonding and mechanical properties in friction stir weld $2014 \mathrm{Al}$ alloy. Materials Letters. 2005;59(23):2948-2952. http://dx.doi. org/10.1016/j.matlet.2005.04.048.

[22] Almeida DT. Análise microestrutural e avaliação mecânica de juntas soldadas por fricção e mistura mecânica (FSW) da liga de alumínio 5182-O [dissertação de mestrado]. Porto Alegre: Universidade Federal do Rio Grande do Sul; 2015.
[23] Fioravanti AS. Soldagem por FSW de ligas de alumínio Alcalad AA2024-T3 e AA7075-T6 [dissertação de mestrado]. Porto Alegre: Universidade Federal do Rio Grande do Sul; 2008.

[24] Zhang YN, Cao X, Larose S, Wanjara P. Review of tools for friction stir welding and processing. Canadian Metallurgical Quarterly. 2012;51(3):250-261. http://dx.doi.org/10.1179/18 $79139512 Y .0000000015$

[25] Zhu XK, Chao YJ. Numerical simulation of transient temperature and residual stresses in friction stir welding of 304L stainless steel. Journal of Materials Processing Technology. 2004;146(2):263272. http://dx.doi.org/10.1016/j.jmatprotec.2003.10.025.

[26] Bhatt KD, Pillai B. Simulation of peak temperature \& flow stresses during friction stir welding of AA7050-T7451 aluminum alloy using hyper works. International Journal of Emerging Technology and Advanced Engineering. 2012;2250:2459.

[27] Keivani R, Bagheri B, Sharifi F, Ketabchi M, Abbasi M. Effects of pin angle and preheating on temperature distribution during friction stir welding operation. Transactions of Nonferrous Metals Society of China. 2013;23(9):2708-2713. http://dx.doi. org/10.1016/S1003-6326(13)62788-0.

[28] Santiago D, Urquiza S, Lombera G, Vedia L. 3D modeling of material flow and temperature in Friction Stir Welding. Soldagem e Inspeção. 2009;14(3):248-256. http://dx.doi.org/10.1590/ S0104-92242009000300008.

[29] Tang W, Guo X, McClure JC, Murr LE, Nunes A. Heat input and temperature distribution in Friction Stir Welding. Journal of Materials Processing \& Manufacturing Science. 1998;2(2):163172.

[30] Gipiela ML, Martins F. Influência dos parâmetros de processo na soldagem da liga de alumínio 5052 pelo processo FSW. In: Associação Brasileira de Engenharia e Ciências Mecânicas. Anais do 8 COBEF-Congresso Brasileiro de Engenharia de Fabricação; 2015; Salvador. Rio de Janeiro: COBEF; 2015. p. 18-22.

[31] Wallace R. Graphing with Excel - Linear regression in Exce [internet page]. Raleigh: NC State University; 2005 [acesso em 24 out. 2017]. Disponível em: https://projects.ncsu.edu/ labwrite/res/gt/gt-reg-home.html 